\title{
Do Workplace Flexibility Policies Influence Time Spent in Domestic Labor?
}

\author{
Mary C. Noonan \\ The University of Iowa \\ Sarah Beth Estes \\ University of Arkansas at Little Rock \\ Jennifer L. Glass \\ The University of Iowa
}

Using data from a U.S. midwestern sample of mothers and fathers, the authors examine whether using workplace flexibility policies alters time spent in housework and child care. They hypothesize that an individual's policy use will lead to more time in domestic labor and that his or her spouse's policy use will lead to less time in domestic labor. Several results support their hypotheses. Mothers who work part-time spend more time in housework and their husbands spend less time in housework. Also, mothers who work at home spend more time in child care. One policy has the opposite of the predicted effect: Wives with flexible work schedules do less housework, and their husbands do more. Overall, mothers' policy use has counterbalancing effects on their own and their spouses' domestic labor time, implying that policy use has little net impact on total domestic labor time within dual-earner families.

Keywords: gender; work-family policies; housework; child care

Jow that dual-earner families are the numerically dominant family form 1 in the United States (Casper \& Bianchi, 2002), much research has focused on parents' time burden of both paid work and family care (Jacobs \&

\footnotetext{
Authors' Note: Correspondence concerning this article should be addressed to Mary C. Noonan, Department of Sociology, The University of Iowa, W140 Seashore Hall, Iowa City, IA 52242-1401; or e-mail: mary-noonan-1@uiowa.edu. This research was supported by a National Science Foundation Dissertation Improvement Award and a grant from the Alfred P. Sloan Foundation. The authors thank Mellisa Holtzman, Nicole Wolensky, and Tor Wynn for research assistance. A previous version of this article was presented at the 2003 annual meeting of the Population Association of America in Minneapolis, MN.
} 
Gerson, 2004). A number of work-family policies have been advocated to help employees cope with these increased demands on their time and energy. The "business case" for such policy changes is framed as the cost to business in lost productivity and higher turnover when workers are stressed by their inability to meet family obligations (Kelly, 1999). The implicit assumption is that instituting the right policies will lower these costs and give employers a competitive edge. The concomitant family case for such policies frames the issue as one of protecting family time and ensuring that parents adequately care for their children. Its implicit assumption is that workplace flexibility will increase the time and energy available for family care. Although a number of empirical studies have attempted to evaluate the accuracy of the business case for work-family policies (Aryee, Luk, \& Stone, 1998; Grover \& Crooker, 1995; Meyer, Mukerjee, \& Sestero, 2001; Scandura \& Lankau, 1997), fewer have focused on the family case. We turn attention here to the claim that workplace flexibility policies will increase the time spent on domestic labor and child care among employed parents.

Workplace flexibility can be achieved in a number of ways. For example, the availability of one popular policy-flextime, or the ability to alter the start and end times of the workday - has more than doubled from 1985, when it was available to $12 \%$ of workers, to 1997 , when it was available to $28 \%$ of U.S. workers (Beers, 2000). Policies might also include flexible scheduling of the number of hours worked each day or number of days worked each week, flexibility in place (work accomplished from home or another off-site location), and reductions in total work hours.

Based on the traditionally higher expectations of care work from mothers, one might expect mothers to be more pressed for time and more likely to seek out and use work-family policies to cope with their work and family demands. However, surveys show high levels of interest in workplace flexibility among both men and women and find that employers prefer to offer these benefits to their top levels of employees who are often predominantly men (Glass \& Fujimoto, 1995; Golden, 2001). A small group of studies has explored the relationship between the use of workplace flexibility policies and the amount of time spent in housework (Bohen \& Viveros-Long, 1981; Kraut, 1989; Silver, 1993; Silver \& Goldscheider, 1994). Results from these studies generally show that policy use is positively related to individual time spent in housework, providing partial support for the notion that workplace flexibility will increase home and family involvement.

One drawback of these studies is that the data used do not provide complete information on both members of married couples, so it is not possible to see whether spouse's policy use affects a respondent's housework and 
child care. This is a significant issue, because prior research has shown that husbands and wives do indeed negotiate effective work and life strategies as a unit, sometimes taking advantage of one partner's ability to obtain work flexibility or to maximize income (Moen \& Yu, 2000). Furthermore, by relying on cross-sectional data, previous studies have been unable to control for unobserved heterogeneity, leading to potentially biased results.

In this article, we ask how dual-earner husbands and wives use work-family policies to cope with their paid and unpaid work. Using unique data from a regional longitudinal sample of husbands and wives, we address the following four questions: (a) Does the use of various workplace flexibility policies alter husbands' and wives' time spent in housework and child care? (b) Is the spouse's use of workplace flexibility related to a respondent's own time spent in housework and child care? (c) Are the impacts of respondent and spousal use of workplace flexibility gender neutral, or do they differ for husbands and wives? and (d) Does policy use increase husbands' and wives' aggregate involvement in housework and child care or simply redistribute a relatively constant level of family work? These issues are important. Although workplace flexibility policies have the potential to strengthen families and increase parental involvement with children, they will not necessarily do so if gender differences emerge in the level or consequences of policy use. For instance, if wives use these policies more than their husbands or policies facilitate domestic work only among women, wives may unintentionally end up doing more housework and child care than they would in the absence of workplace flexibility. In this way, family-friendly policies could further institutionalize domestic labor as wives' marital responsibility (Bergmann, 1998) and cement their status as secondary wage earners (Glass, 2004; Stratton, 2001).

\section{Background}

The amount of time Americans spend on housework has been declining during the past three decades, from an average of 17.5 hours per week in 1965 to 13.7 hours per week in 1995 (Bianchi, Milkie, Sayer, \& Robinson, 2000). Changing norms of cleanliness, the introduction of labor-saving devices, and the fact that more women are in the labor force are some proposed explanations for the overall decline in housework. Parental availability to provide full-time child care has also steadily declined since the 1960s as a result of the increase in maternal employment and single parenthood. This has led to concern among some social critics, because parental time investments in children are connected to childrens' well-being (Hewlett, 1991). ${ }^{1}$ 
Work-family policies are more available to employees today, in part, as a response to this notion that many working parents lack the time needed to tend to their families and homes. Thus, exploring whether workplace flexibility increases actual hours of family time is an important social issue.

It seems logical to assume that work-family policies would be more appealing to women than men, because women still shoulder the main responsibility for care work within families. For example, although the gender gap in domestic work has narrowed during the past three decades, women still do considerably more housework and child care than men do. In 1995, women performed 17.5 hours of housework per week on average, whereas men performed only 10 hours (Bianchi et al., 2000). A gender gap also exists for child care time; married mothers spent on average 1.7 hours per day in child care in 1998, compared to 1.0 hour per day for married fathers (Bianchi, 2000).

Three main theoretical perspectives exist within the literature predicting time spent in housework: time availability, relative resources, and gender (reviewed in Bianchi et al., 2000). The time availability perspective suggests that the division of household labor is rationally allocated according to the availability of household personnel in relation to the amount of housework to be done (Coverman, 1983). The relative resources perspective argues that the level of relative resources (such as income, education, or occupation) an individual brings to a relationship determines how much housework he or she does, either because of efficiency maximization processes (Becker, 1991) or through power processes (Blood \& Wolfe, 1960). Finally, the gender perspective argues that housework is a symbolic enactment of gender relations, not a rational choice due to time availability, to the maximization of efficiency or to the conversion of external resources into the exercise of power in the home (West \& Zimmerman, 1987). Some authors have theorized that because housework is more mundane than child care and offers fewer intrinsic rewards to most people, the predictors of housework time might not be informative predictors of child care time (Ishii-Kuntz \& Coltrane, 1992). To allow for this possibility, we treat housework and child care as distinct activities in our study. However, because we conceptualize child care time as time spent caring for children (e.g., bathing, feeding, etc.), not as time spent in leisure activities with children (e.g., playing, watching television, etc.), we expect the forces that shape housework time to be similar to those that shape child care time.

In this article, we add to a growing body of research that expands the time availability perspective to explore whether other work-related factors besides work hours - including work schedules and work locations_-might influence the time spent on family responsibilities. Workplace flexibility policies 
can aid parents in attending to their family responsibilities by allowing them to arrange their schedules around their family responsibilities or to take care of these responsibilities during work time. For instance, schedule flexibility could help parents more easily attend to rigidly scheduled family responsibilities (e.g., preparing the evening meal, picking up children from school, etc.). Working at home may free up time by eliminating the journey to work and as a result offer individuals more time to accomplish care work. Individuals working at home may also be able to perform more care work than those working on-site, if they are able to perform their job and family tasks simultaneously (Osnowitz, 2005; Silver, 1993).

Empirical studies have tested these extensions of the time availability perspective to see if certain aspects of work structure do indeed have important influences on housework time. For instance, Presser (1994) found that housework was shared more equitably in couples that work nonoverlapping shifts; specifically, husbands spent more time in female-typed housework tasks when they worked a nondaytime or rotating shift and their wives worked a day shift. In a qualitative study of women real estate agents, Wharton (1994) found that the realtors and their husbands shared housework more equitably compared to other dual-earner couples and speculates that more equitable sharing is a result of the nonoverlapping work schedules many realtors have with their husbands. Nock and Kingston (1988) found evidence that fathers' time with children was also affected by wives' work schedules; when wives worked at night, fathers spent more time with their children, mainly watching television. Similarly, research done by Brayfield (1995) showed that when mothers worked at night and fathers did not, fathers took on more responsibility for child care.

Other authors have examined how the spatial location of work is related to time spent in housework. Silver (1993) found that working-class women "homeworkers" (i.e., those who work exclusively from home) spent more time in housework and child care than their on-site counterparts. Work at home had little effect on men's contributions to domestic work. One explanation for this may be that women often work at home so that they can more easily attend to their care work responsibilities, whereas the decision to work at home for men is typically independent of these concerns (Gerson \& Kraut, 1988; Gurstein, 1991; Kraut \& Grambsch, 1987). Kraut (1989) also found that women home-based workers performed more domestic labor than on-site workers. He reports that, on average, women clerical home-based workers did 9 additional hours of housework and child care per week compared to office workers who did not work at home. In another study, Silver and Goldscheider (1994) found no association between hours worked at 
home and time spent in housework for women. However, this study used a continuous measure indicating the number of hours worked at home, whereas Silver (1993) and Kraut (1989) used a dichotomous measure of homeworker.

Only a few studies to date have explored the relationship between employees' use of daily schedule flexibility and time spent in domestic labor. Using data from a regional sample of workers, Bohen and Viveros-Long (1981) compared flextime workers to standard time workers with respect to time spent on family chores. They found that schedule flexibility increased time on family chores but only for single mothers. For all other subgroups, workers on flextime did not spend significantly more time on family work than those on standard time. Silver and Goldscheider (1994) used a broader set of work-family policies to examine the association between workplace family responsiveness and weekly housework hours for two cohorts of women from the National Longitudinal Surveys ( 34 to 44 years old in 1987 vs. 52 to 66 years old in 1989). Using a work-family responsiveness index that combined time off for child care, child day care, paid personal time, and flexible work hours, they found that the more work-family benefits a woman had available to her, the more hours of housework she performed, but the relationship was only significant for the older cohort of women. Because the responsiveness index incorporated multiple aspects of work-family policies, their analysis may have obscured relationships between specific work-family policies and time spent in domestic labor. Furthermore, the survey data used by Silver and Goldscheider only identified whether the respondents were offered each of the benefits. But the technical availability of benefits does not necessarily imply that workers used the benefits, a theoretically critical difference in evaluation research.

\section{Current Investigation}

In this article, we expand the time availability perspective by asking whether using workplace flexibility policies affects wives' and husbands' time spent in housework and child care. We extend previous related research in four important ways. First, we examine the distinctive impact of three specific policy measures on housework and child care time-schedule flexibility, work at home, and reduced work hours. Second, we examine not only the impact of the respondents' use of workplace flexibility policies on time spent in housework and child care but also the impact of the spouses' use of workplace flexibility policies on the respondents' domestic labor time. Third, although some studies on the topic of work-family policies and domestic 
labor have limited their investigations to women, we include both men and women in our analysis. Finally, we examine how policy use, not simply availability, is related to domestic work time.

We expect that our measures of schedule flexibility, work at home, and reduced work hours will be associated with more time spent performing housework and providing child care. If the respondent's spouse uses a policy, we expect that this use will be associated with less time in housework or child care for the respondent (because it is presumed that the spouse is assuming more of the home responsibilities). We predict that the direction of these effects will be the same for wives and husbands but that wives' policy use will have a larger impact both on their own housework or child care time and on their husbands' housework or child care time. This prediction is based on prior research that shows that mothers are more likely than fathers to adjust their home responsibilities to their work lives (Hochschild, 1989) and research that finds that fathers are more likely than mothers to make adjustments in their domestic labor time according to their spouses' availability (Goldscheider \& Waite, 1991; Presser, 1994).

\section{Data and Measures}

The data come from a U.S. midwestern longitudinal sample of pregnant and postpartum women. The data provide numerous measures of policy use and time spent in care work and so are well suited to our research questions. Furthermore, the women's husband or cohabiting partner was also interviewed, which provides us with spousal data that many previous analyses are lacking. The initial sampling frame consisted of all mothers in five midwestern counties who were employed at the time they became pregnant and who gave birth between December 1991 and September 1992 at one of four regional hospitals. All women using the hospitals for maternity care were eligible to participate in the survey. From this sampling frame, 387 women were randomly selected (according to the month they gave birth), and 321 of these women were actually contacted in their last trimester of pregnancy. Thus, the effective response rate for the original survey was $83 \%$. Follow-up surveys at 6 and 12 months postpartum were completed with 307 of the original 321 respondents. Demographic comparisons with national data showed this sample was representative of U.S. mothers in age, education, occupational distribution, family size, and marital status, but not race (Whites were overrepresented). The fourth round of interviews was performed from 1998 to 1999, approximately 7 years after the initial round of 
interviews. Attrition with time reduced the sample to $61 \%$ of the original respondents (i.e., 196 women). Attrition was more severe for those at the lowest levels of education, resulting in a sample that overrepresented professional and managerial workers who had above average education and earnings and whose partners also had significantly higher earnings than a nationally representative sample of mothers and fathers. However, in other respects (age, family size, marital status, hours worked per week), the sample remained broadly representative. ${ }^{2}$ During the first and fourth waves of the survey, mothers were asked questions concerning their use of workplace flexibility policies and questions about their time spent in housework and child care. Data were not collected on these measures during the second and third waves of the survey. Fathers were interviewed about their work and family lives only during the fourth wave of the survey.

We perform two sets of analyses. The first is cross-sectional and the second is longitudinal. The first analysis is restricted to the fourth wave of data when the target child was approximately 7 years old, because we want to investigate the relationship between policy use and domestic labor for mothers and fathers. This cross-sectional analysis also allows us to look at the relationship between spousal policy use and respondent's domestic labor time. One limitation of the cross-sectional analysis is that we are unable to control for unmeasured individual characteristics that may affect both policy use and time spent in domestic work, such as respondent's motivation, ambition, or ability. Failing to control for these factors could potentially lead to biased results.

Our supplemental longitudinal analysis addresses this problem. In this analysis, we use two waves of data - the first and the fourth waves- to estimate two different types of models: fixed-effects models and randomeffects models. Fixed-effects models examine within-person variation across time and in doing so control for any time invariant unobserved individual factors that may be correlated with the dependent variable. Randomeffects models assume that the unobserved characteristics are not correlated with the dependent variable, and this stronger assumption allows for more precise estimates. Random-effects models are preferable to simple crosssectional models, however, because they use the variation both across and within individuals in estimating the model. We conduct a Hausman test to determine whether fixed-effects or random-effects models are more suitable for our analysis. ${ }^{3}$ Finally, because we do not have data on fathers' policy use and domestic labor time at both waves, the longitudinal analysis only explores the relationship between mothers' policy use and domestic work. 


\section{Cross-Sectional Sample and Measures}

As mentioned, the data for our cross-sectional analysis come from the fourth wave of the study. Because we are interested in how spouses' use of workplace flexibility policies may affect respondents' domestic labor, we limit our sample to individuals in married and/or cohabiting dual-earner couples. For simplicity, we refer to these men and women as husbands and wives throughout the article, although a small percentage of them are in fact cohabiting (we discuss this further below). The unit of analysis is the individual, although the men and women in the study are each other's partners. For the few variables (father's education, mother's attitudes, and father's attitudes) that have missing data, we impute the missing cases with the sample average for that variable. The final sample size is $110 .^{4}$

The dependent variables are time spent in housework and child care, and our main independent variables are mothers' and fathers' use of workplace flexibility policies. The survey asked respondents to separately identify the number of hours spent in housework (cooking, cleaning, shopping, etc.) and child care (bathing, dressing, reading to them, etc.) on workdays and nonworkdays. We then multiplied these responses by five and two, respectively, based on the assumption that this is the typical split of workdays or nonworkdays within a given week. Next, we categorized time spent in housework and child care into three separate measures: total weekly time, total weekly time on workdays, and total weekly time on nonworkdays. We do this because it is likely that workplace flexibility policies will have a larger impact on family responsibilities carried out on workdays compared to nonworkdays.

The main independent variables are the set of three work flexibility policies: schedule flexibility, work at home, and reduced work hours. For all policies, we use measures of use, as opposed to availability, because our theory is based on the notion that individuals must use policies for them to have an impact on care work. ${ }^{5}$ Schedule flexibility is a dichotomous variable equal to 1 if a respondent indicated that he or she set the days or hours of his or her work schedule most of the time (i.e., daily or weekly). Work at home is a dichotomous variable equal to 1 if a respondent indicated that he or she usually worked at least 5 hours a week of his or her regular work schedule from home (not including overtime work). ${ }^{6}$ Finally, reduced work hours is also a dichotomous variable, equal to 1 if the respondent works fewer than 35 hours per week and if he or she chose to work part-time. We also include three separate indicators for whether the respondent's spouse uses each of these workplace flexibility policies. ${ }^{7}$ Each of these policy measures is consistent with (in the case of hours worked at home and reduced work hours) or better than (in 
the case of schedule flexibility) those found in available national data sets (see, e.g., the National Study of the Changing Workforce, Bond \& Galinsky, 2001). To our knowledge, no other data set contains such rich policy and family measures.

\section{Longitudinal Sample and Measures}

The data for the longitudinal analysis come from the first and fourth waves of the study. Our analytic subsample includes women who were employed at both waves, were either married to or cohabiting with (the same) employed men at both waves, and had nonmissing data on the key variables included in the model. The final sample size is 172 person-years (i.e., 86 women at two points in time). ${ }^{8}$

In this analysis, our dependent variable is the mothers' responsibility for care work. Unfortunately, the question asking respondents to identify the number of hours spent in housework was asked only during the fourth wave of the study and therefore could not be used in the longitudinal analysis. Hours of housework time is the ideal measure to use in our analysis, because our theories relating policies to care work are based on absolute time, not the sharing of responsibilities (see Presser, 1994, and Goldscheider and Waite, 1991, for a more detailed discussion of absolute vs. relative measure of care work). However, because we are examining responsibility longitudinally, we can tell whether a woman does more or less of the total family housework, over time, as a function of policy use with time.

The housework measure is based on a question that asks the respondent to identify on a scale of 1 to 5 who in the household (husband always, husband usually, husband and wife equally or paid help or other household member, wife usually, and wife always) does the following six tasks: preparing meals, food shopping, taking care of children, daily housework, cleaning up after meals, and laundry. We summed the respondent's answers for the six different tasks and then divided the sum by six to arrive at an average level of care work responsibility. Values were coded so that a higher score indicates that the wife assumes more responsibility for care work.

In the longitudinal analysis, our main independent variables are measured as months of employment during which each of the following family-responsive policies were used between the first and fourth interviews - months of work schedule flexibility, months of work at home, and months of reduced work hours. These policies are defined the same as above. Because the length of time between the first and fourth interviews was approximately 7.5 years, the policy month variables range from 0 to $90(7.5 \times 12=90)$. 


\section{Control Variables}

We include a set of control variables that are likely associated with time spent in domestic work and work-family policy use. Because of our small sample sizes, we are cautious about the number of control variables included in the models; if the statistical models are too complex for the data, estimated coefficients could be biased. As a result, we include only seven control variables in our models.

To address the time availability perspective, we include a dummy variable equal to 1 if the respondent works overtime, defined by us as more than 45 hours per week. Forty-five hours is a commonly used benchmark to indicate overtime work and is equivalent to $10 \%$ or more hours beyond the average amount worked in our sample (i.e., 41 hours per week). We measure time availability in this way instead of with a continuous measure of work hours, because work hours are highly correlated with the policy measure of reduced work hours. We expect that if the respondent works overtime, he or she will do less housework or child care.

To control for relative resources, we include measures of income and education. Respondent's logged income is created from a question asking the respondent to report his or her annual income before taxes; a small number of respondents did not report an actual dollar amount but instead identified a salary range. For these respondents, we assigned the midpoint of the appropriate range. Income is expected to be negatively related to domestic labor time, because individuals who earn more are more able to "buy out" of housework and child care via domestic services (take-out meals, nannies, cleaning services). A variable indicating relative earnings is also included in the analysis. This variable is measured as the ratio of respondent's earnings to the total family earnings (respondent's and spouse's income) multiplied by 100; it ranges from 0 to 100 . We include it to tap the resource-bargaining perspective, which states that the spouse with more resources within the family and thus more power will negotiate his or her way out of housework and child care (Brines, 1994). This variable also tests the economic exchange perspective. According to this perspective, husbands and wives rationally allocate housework or child care to maximize overall usefulness or efficiency in the household (Becker, 1991). The spouse who earns more will do less housework, because he or she has more to lose by spending time in housework instead of the labor market. Both perspectives predict that as share of total earnings increases, fewer hours of housework and child care will be performed.

Years of education is a continuous variable equal to the number of years of formal education completed by the respondent. ${ }^{9}$ Studies have found that 
controlling for income, highly educated women spend more time in child care than other women, potentially because they place a higher value on their time with their children (e.g., see Zick, Bryant, \& Osterbacka, 2001). On the other hand, education is likely to be correlated with earning potential, meaning that more highly educated women and men would be able to buy out of housework and child care.

To address the gender perspective, we include a gender role attitudes scale that measures the respondents' beliefs about the benefits and costs of labor force participation to women and their families. The value of this variable is obtained by summing the level of agreement or disagreement with five 5-point Likert-type scale attitudinal items and then dividing by five. If a respondent did not answer one of the items, we imputed the mean response for that item. The questions used to create this measure include the following: "It is much better for everybody involved if the man earns the money and the woman takes care of the home and the children" (reverse coded); "Both the husband and the wife should contribute to the family income"; "The father should spend as much time as the mother looking after the daily needs of his children"; "It is more important for a wife to help her husband's career than to have one herself"(reverse coded); and "A mother with preschoolers should be able to work just as many hours per week as their father." The internal reliability of this scale is .63 as measured by Cronbach's alpha coefficient. For the longitudinal analysis, only two attitude questions were asked at both waves: the first one mentioned above and "A mother who works outside the home can have just as good a relationship with her children as a mother who does not." These two items were not combined into a scale because the internal reliability was too low. Therefore, we include them in the regression model as two separate items. According to the gender perspective, we expect the attitude variables to be positively related to care work time for women and negatively related to care work time for men, because parents who support a traditional division of domestic labor between husband and wife will likely adhere to such a division in their own homes.

The number of children is a continuous variable equal to the number of children (including step, adoptive, and foster) under the age of 18 years currently living with the respondent. Because the initial sampling frame included only pregnant and postpartum women, all respondents have at least one child. We expect this variable to be positively related to care work time, because more children in the household results in more housework and child care. Finally, the spouse's time in care work is also included in the models. We assume that a spouse's time is a substitute for respondent's time, and so this measure should be negatively related to respondent's care work time. 
We do not include a variable indicating whether the couple is married, because only a very small percentage of the couples were cohabiting (less than $4 \%$ in both samples), and models including an indicator of marriage produced results substantively the same as those presented here. A set of dummy variables indicating husbands 'and wives' joint work schedules was also originally included in the models (i.e., both work days, both work evenings, wife works days and husband works evenings, and wife works evenings and husband works days). Compared to those couples in which both the husband and wife work the day shift, husbands do more child care (approximately 3.6 hours more per week) when they work the day shift and their wives work the evening shift. This result is consistent with prior research (Brayfield, 1995; Nock \& Kingston, 1988). For the housework models, the set of work schedule dummy variables was not significant. Our main results (discussed below) were substantively similar without the work schedule dummy variables; so to preserve degrees of freedom, we did not include them in the final models.

\section{Method}

The first step in our analysis is to estimate models predicting time spent in housework and child care as a function of workplace flexibility policy use and other relevant control variables representing the time availability, relative resource, and gender perspectives. We use Seemingly Unrelated Regression (SUR) techniques to estimate our cross-sectional models, because the error terms in the wives' regression models are likely correlated with the error terms in the husbands' models (Zellner, 1962). Correlation is likely, because these husbands and wives are part of a couple; they are not selected from independent populations. SUR estimates take into account unobserved and unmeasured factors that are common to husbands and wives and that are likely to affect their time in domestic labor (e.g., size of home). In other words, SUR takes into account the correlation between the residuals of the regression equations for the husbands and wives. In turn, this improves the efficiency of the regression estimates (Kennedy, 2003). Because we expect the relationship between policy use and domestic labor to be strongest on workdays, we present only the findings for the models predicting total weekly time on workdays; results from models predicting total weekly time (including nonworkdays) are presented in the appendices.

For the longitudinal analyses, we estimate both fixed-effects and randomeffects models predicting mothers' responsibility for care work as a function of months of policy use and the control variables. We run a Hausman test to 
see whether fixed or random-effects models are preferable. Finally, multicollinearity is not a serious concern in either set of analyses; the variance inflation factor is between 1.4 and 1.7 in each model.

\section{Results}

\section{Cross-Sectional Results}

Descriptive statistics for variables in the analysis are shown in Table 1. Results of $t$ tests show that mothers spend more time in housework and in child care than do fathers (both in total weekly and total weekly on workdays), although the magnitude of the difference is larger for housework than it is for child care. For instance, during the workweek, mothers spend about 1.5 times more time in housework than fathers do: 12 hours versus 8 hours. Mothers also devote about 3 hours more to child care during the workweek than fathers do: 12.5 hours versus 9.6 hours.

Table 1 also shows that mothers and fathers are equally likely to use flexible scheduling. Flexible scheduling is also the most heavily used of the three policies we examine, with $42 \%$ of the mothers and $35 \%$ of the fathers using flexible scheduling on a weekly basis. A higher percentage of mothers compared to fathers, $12 \%$ versus $5 \%$, work at least 5 hours per week from home. And mothers use reduced work hours more than fathers, 35\% of mothers versus $2 \%$ of fathers.

With respect to work hours, only one tenth of mothers work more than 45 hours a week, in contrast to approximately half of the fathers. On average, mothers work 35.3 hours per week, and fathers work 46.9 hours per week (statistics not shown in table). Mothers and fathers have similar levels of education, but fathers earn substantially more income than the mothers $(\$ 47,000$ vs. $\$ 33,000)$. Mothers earn approximately two fifths of family income on average, and fathers earn about three fifths of family income. Finally, men and women in the sample have similar gender role attitudes and, on average, have approximately 2.4 children.

Next, we investigate the relationship between policies and domestic labor time, controlling for relevant work, family, and demographic variables. We first discuss models predicting housework time and then discuss those predicting child care time. The first four columns of each table show the results for the sample of mothers, and the last four columns show the results for the sample of fathers.

Regression results predicting weekly housework time on workdays are shown in Table 2. Coefficients in Model 1 show that net of control variables, 
Table 1

Descriptive Statistics

\begin{tabular}{|c|c|c|c|c|}
\hline \multirow[b]{2}{*}{ Variable } & \multicolumn{2}{|c|}{ Mothers } & \multicolumn{2}{|c|}{ Fathers } \\
\hline & $M$ & $S D$ & $M$ & $S D$ \\
\hline \multicolumn{5}{|l|}{ Housework } \\
\hline Total weekly hours of housework & $21.35 \dagger$ & 9.25 & $15.75 \dagger$ & 8.61 \\
\hline $\begin{array}{l}\text { Total weekly hours of housework } \\
\text { on workdays }\end{array}$ & $11.92 \dagger$ & 7.07 & $8.11 \dagger$ & 5.55 \\
\hline \multicolumn{5}{|l|}{ Child care } \\
\hline Total weekly hours of child care & $23.58 \dagger$ & 12.08 & $20.33 \dagger$ & 10.45 \\
\hline $\begin{array}{l}\text { Total weekly hours of child care } \\
\text { on workdays }\end{array}$ & $12.48 \dagger$ & 7.55 & $9.62 \dagger$ & 5.73 \\
\hline \multicolumn{5}{|l|}{ Policy use } \\
\hline Schedule flexibility & 0.42 & & 0.35 & \\
\hline Work at home & $0.12 \dagger$ & & $0.05 \dagger$ & \\
\hline Reduced work hours & $0.35 \dagger$ & & $0.02 \dagger$ & \\
\hline \multicolumn{5}{|l|}{ Controls } \\
\hline $\begin{array}{l}\text { Works overtime ( } 45 \text { hours } \\
\text { and above) }\end{array}$ & $0.10 \dagger$ & & $0.47 \dagger$ & \\
\hline Education & 14.94 & 2.97 & 14.58 & 2.46 \\
\hline Annual income & $\$ 32,673 \dagger$ & $\$ 35,381$ & $\$ 47,028 \dagger$ & $\$ 22,187$ \\
\hline Logged annual income & $10.10 \dagger$ & 0.80 & $10.65 \dagger$ & 0.48 \\
\hline $\begin{array}{l}\text { Percentage of total } \\
\text { family income }\end{array}$ & $38.40 \dagger$ & 17.22 & $61.59 \dagger$ & 17.22 \\
\hline Gender role attitudes & 2.34 & 0.60 & 2.35 & 0.51 \\
\hline Number of children & 2.39 & 0.82 & 2.39 & 0.82 \\
\hline$N$ & 110 & & 110 & \\
\hline
\end{tabular}

$\dagger p<.10$, significantly different between mothers and fathers.

schedule flexibility is associated with approximately 3.5 fewer hours of housework during the workweek among mothers. Because the average mother does 12 hours of housework during the workweek, this translates into a $29 \%$ decrease in total housework time. This finding is in contrast to our expectation that workplace flexibility policy use would be positively related to housework time. Model 2 shows that when the husbands' policy use is added to the model, wives' reduced work hours are positively associated with their housework time; reduced work hours are associated with approximately 3 more hours of housework during the workweek among mothers (a 25\% increase from the average). This result is consistent with our expectations. Results from Model 2 also show that husbands' workplace policy use is unrelated to mothers' housework time. 
Table 2

\section{Regression Results Predicting Weekly Hours of Housework on Workdays}

\begin{tabular}{|c|c|c|c|c|c|c|c|c|}
\hline \multirow[b]{2}{*}{ Variable } & \multicolumn{4}{|c|}{ Mothers } & \multicolumn{4}{|c|}{ Fathers } \\
\hline & Model 1 & $S E$ & Model 2 & $S E$ & Model 1 & $S E$ & Model 2 & $S E$ \\
\hline \multicolumn{9}{|l|}{ Respondent's policy use } \\
\hline Schedule flexibility & $-3.47 *$ & 1.41 & $-4.08 * *$ & 1.49 & -0.58 & 1.09 & -1.40 & 1.07 \\
\hline Work at home & 3.15 & 2.22 & 3.23 & 2.23 & -1.34 & 2.60 & -0.12 & 2.51 \\
\hline Reduced work hours & 2.68 & 1.71 & $3.08 \dagger$ & 1.73 & 1.16 & 4.24 & 4.24 & 4.15 \\
\hline \multicolumn{9}{|l|}{ Spouse's policy use } \\
\hline Schedule flexibility & & & 1.18 & 1.46 & & & $2.97 * *$ & 1.09 \\
\hline Work at home & & & -0.03 & 3.28 & & & -0.92 & 1.53 \\
\hline Reduced work hours & & & -4.48 & 5.58 & & & $-2.99 *$ & 1.27 \\
\hline$R$ squared & .12 & & .12 & & .15 & & .22 & \\
\hline$N$ & 110 & & 110 & & 110 & & 110 & \\
\hline
\end{tabular}

Note: All models include controls for working overtime, education, logged income, percentage of family income earned by respondent, attitudes, number of children, and spouse's housework hours.

$\dagger p<.10 . * p<.05 . * * p<.01$.

Results for fathers' housework time are shown in the last four columns of Table 2. Fathers' use of workplace flexibility policies is unrelated to housework time (see Model 1). With respect to the impact of spousal policy use, we find that if a wife has a flexible schedule, the husband does significantly more housework compared to other men (see Model 2). Compared to men married to women with nonflexible schedules, men married to women with flexible schedules do, on average, 3 additional hours of housework during the workweek. Because the average father performs about 8 hours of housework during the workweek, this translates into a $37 \%$ increase in housework time. This finding contradicts our hypothesis that spousal policy use would lead to less domestic labor. But this finding does suggest that husbands compensate for the reduction in housework done by their "flex-time wives" by doing more around the home. Also, if a man's wife works reduced hours, he does about 3 hours less of housework per week, compared to other men. This is equal to a $37 \%$ decrease in the average amount of housework time. Again, this finding suggests that husbands adjust to the increase in housework accomplished by their part-time wives by decreasing their housework time by approximately the same amount. 


\section{Table 3}

\section{Regression Results Predicting Weekly Hours of Child Care on Workdays}

\begin{tabular}{|c|c|c|c|c|c|c|c|c|}
\hline \multirow[b]{2}{*}{ Variable } & \multicolumn{4}{|c|}{ Mothers } & \multicolumn{4}{|c|}{ Fathers } \\
\hline & Model 1 & $S E$ & Model 2 & $S E$ & Model 1 & $S E$ & Model 2 & $S E$ \\
\hline \multicolumn{9}{|l|}{ Respondent's policy use } \\
\hline Schedule flexibility & -1.32 & 1.43 & -1.77 & 1.50 & -0.48 & 1.13 & -0.86 & 1.16 \\
\hline Work at home & $5.80^{*}$ & 2.31 & $5.45^{*}$ & 2.35 & -0.42 & 2.71 & -0.12 & 2.71 \\
\hline Reduced work hours & -0.20 & 1.74 & -0.13 & 1.77 & 4.88 & 4.42 & 6.58 & 4.48 \\
\hline \multicolumn{9}{|l|}{ Spouse's policy use } \\
\hline Schedule flexibility & & & 0.37 & 1.50 & & & 1.48 & 1.17 \\
\hline Work at home & & & 1.16 & 3.37 & & & 1.60 & 1.72 \\
\hline Reduced work hours & & & -4.56 & 5.77 & & & 0.38 & 1.36 \\
\hline$R$ squared & .17 & & .18 & & .10 & & .14 & \\
\hline$N$ & 110 & & 110 & & 110 & & 110 & \\
\hline
\end{tabular}

Note: All models include controls for working overtime, education, logged income, percentage of family income earned by respondent, attitudes, number of children, and spouse's child care hours.

$* p<.05$.

Results of the regressions of child care time on policy use are shown in Table 3. Consistent with theoretical expectations, Models 1 and 2 show that work at home is associated with more time spent in child care for mothers. Mothers who work at home spend nearly 6 additional hours in child care per workweek compared to mothers who do not work at home. Because the average mother spends 12 hours of time in caring for her children per week, this translates into approximately a 50\% increase. Husbands' policy use does not affect mothers' weekly child care time.

Results for fathers' child care time are shown in the last four columns of Table 3. Neither fathers' workplace flexibility policy use (see Model 1) nor their spouses' policy use (see Model 2) is related to their weekly child care time on workdays.

In the preceding analyses, we have investigated the relationship between workplace flexibility policy use and time spent in domestic labor for women and men in dual-earner couples. Of the 12 possible associations between respondent's policy use and domestic labor time, only the 2 positive relationships between (a) mothers' reduced work hours and housework and (b) mothers' work at home and child care meet our theoretical expectations. The negative 
relationship between flexible scheduling and housework time among mothers is in the opposite direction of what we expected. Our hypothesis that spousal policy use would be negatively associated with time spent in domestic labor is only supported in 1 out of 12 possible scenarios. If a wife works reduced work hours, the husband performs less housework. Contrary to our expectations, if a wife uses flexible scheduling, the husband spends morenot less-time in housework.

Policy use is not associated with mothers' or fathers' housework time on nonworkdays (results not shown). The results for total weekly housework time (nonworkdays and workdays combined) are similar to those discussed above (see Appendix A). The one exception is that mothers' reduced work hours do not have a statistically significant impact on mothers' total weekly housework time, suggesting that mothers who are employed full-time confine more of their housework to their days off from paid work. With respect to child care time, we find the same pattern of results that we discuss above when examining time spent on child care on nonworkdays (results not shown) and for the entire week (see Appendix B). Mothers who work at home spend more time caring for their children, all else equal.

\section{Longitudinal Results}

Because cross-sectional analyses are vulnerable to unmeasured individual characteristics that may affect both policy use and time spent in domestic labor, we also perform a longitudinal analysis that addresses this potential problem. The Hausman test indicated that random-effects models are more suitable for our analysis than fixed-effects models. We can infer from this that our estimates are not subject to unobserved heterogeneity bias.

We estimate a model relating the months of policy use to mothers' care work responsibility at two points in time. As mentioned, we do not have longitudinal data for fathers; nor do we have measures of hours spent in care work at both waves. Thus, the dependent variable is responsibility for care work rather than actual hours of care work, and our sample is restricted to women only.

Descriptive statistics for variables in the longitudinal analysis are shown in the first four columns of Table 4. Mothers' responsibility for care work increased very slightly during this 7-year period, from 3.7 to 3.8 on a 5-point scale. With respect to policy use, flexible scheduling was used the most during this period: Mothers averaged 2.75 years ( 33 months/ 12 months) of flexible scheduling. Work at home was used an average of 9 months, whereas reduced work hours was used, on average, a little more than a year.

Mothers were less likely to work overtime at the fourth survey compared to the first survey. Mothers' annual income increased with time, but mothers' 


\section{Table 4}

\section{Descriptive Statistics and Random-Effects Regression Results Predicting Housework Responsibility, Mothers Only}

\begin{tabular}{|c|c|c|c|c|c|c|}
\hline \multirow[b]{2}{*}{ Variable } & \multicolumn{2}{|c|}{ Time 1} & \multicolumn{2}{|c|}{ Time 4} & \multirow[b]{2}{*}{ Coefficient } & \multirow[b]{2}{*}{$S E$} \\
\hline & $M$ & $S D$ & $M$ & $S D$ & & \\
\hline Mothers' housework responsibility ${ }^{\mathrm{a}}$ & 3.69 & 0.56 & 3.82 & 0.57 & & \\
\hline \multicolumn{7}{|l|}{ Months of mothers' policy use } \\
\hline Schedule flexibility & 0.00 & - & 32.70 & 34.52 & -0.00 & 0.00 \\
\hline Work at home & 0.00 & - & 9.29 & 22.81 & 0.00 & 0.00 \\
\hline Reduced work hours & 0.00 & - & 13.69 & 30.35 & 0.00 & 0.00 \\
\hline \multicolumn{7}{|l|}{ Controls } \\
\hline $\begin{array}{l}\text { Works overtime ( } 45 \text { hours } \\
\text { and above) }\end{array}$ & 0.19 & & 0.13 & & -0.19 & 0.11 \\
\hline Education & 15.19 & 3.00 & 15.19 & 3.00 & -0.01 & 0.02 \\
\hline Logged annual income & 9.92 & 0.48 & 10.21 & 0.82 & 0.12 & 0.09 \\
\hline Percentage of total family income & 43.34 & 11.75 & 39.92 & 17.83 & $-0.01 * *$ & 0.00 \\
\hline $\begin{array}{l}\text { Gender role attitudes ("Mom who } \\
\text { works outside home. ..") }\end{array}$ & 1.64 & 0.97 & 1.51 & 0.78 & 0.02 & 0.04 \\
\hline $\begin{array}{l}\text { Gender role attitudes ("It is better } \\
\text { if man earns money } \\
\text { and woman. ..") }\end{array}$ & 1.80 & 1.00 & 2.01 & 1.04 & 0.03 & 0.04 \\
\hline Number of children & 0.74 & 0.94 & 2.31 & 0.77 & -0.00 & 0.04 \\
\hline$R$ squared & & & & & .10 & \\
\hline$N$ & 86 & & 86 & & 172 & \\
\hline
\end{tabular}

a. Scale of 1 to 5 , with 5 equal to wife completely responsible.

$* * p<.01$.

contribution to family income decreased slightly. Gender role attitudes remained relatively constant, and the number of children increased by approximately 1.5 .

The last two columns of Table 4 show the results from the randomeffects regression models. Months of policy use (of any type) are unrelated to mothers' care work responsibility. There is no evidence that the use of workplace flexibility policies encourages wives to assume a greater share of care work within the family.

\section{Discussion and Conclusion}

This article examines whether individual and spousal use of workplace flexibility policies is related to time spent in housework and child care. In 
general, we find that policy use either by an individual or by his or her spouse is unrelated to domestic labor time; only 5 of the 24 relationships between policy use and domestic labor were statistically significant. This finding is bolstered by our longitudinal results for mothers, which show no relationship between mothers' use of workplace flexibility policies and care work responsibility.

Our results show that two policies are related to housework time. On average, mothers who work a flexible schedule do less housework and their husbands do more. And mothers who work reduced hours do more housework and their husbands do less. The relationship between flexible scheduling and housework is the opposite of what we predicted. It could be that mothers who work flexible schedules, instead of a standard 9 to 5 work schedule, are not at home either in the early morning or in the early evening when routine family care work often needs to be performed (e.g., preparing meals). This may create a situation in which the mother is simply not available to perform the necessary housework and the husband of the "flex-time mother" must step in to perform the necessary chores. The positive relationship between mothers' reduced work hours and their housework time and the negative relationship between mothers' reduced work hours and husbands' housework time support our initial predictions.

Mothers' use of these two policies shifts both mothers' and fathers' housework time by similar amounts (about 3 to 4 hours), but in counterbalancing directions, meaning that mothers' use of the given policies does not appear to increase the couples' total time spent in housework. Instead, a substitution effect seems to be operating, in which mothers who use these policies perform more or less housework and their husbands react by doing the opposite.

Only one of the workplace flexibility policies is related to child care time. We find that compared to mothers who work predominately on-site, mothers who work some time at home spend more time caring for their children during the workweek. A mother's spatial flexibility may be part of a family's strategy to reduce or eliminate paid child care by creating a situation in which she is able to perform her paid work and care for her children simultaneously (Osnowitz, 2005). Whereas the housework results show a pattern of substitution between husband and wife (and therefore no net impact of housework time), the child care results imply a net positive impact of child care time performed within the family. Mothers who work at home are likely replacing paid child care workers or relatives as their children's caregivers for at least part of the workweek.

In addition to documenting the relationship between individual and spousal use of workplace flexibility policies and domestic labor time, one 
of our main goals in this article was to explore whether the relationships differed for mothers and fathers. Indeed, for the relationships that we do find, stark gender differences exist. In general, mothers' policy use is related to their care work time, but their spouses' policy use has no impact on care work time. For fathers, the pattern is reversed: Fathers' time in care work is unaffected by their own policy use but is sensitive to their wives' policy use (i.e., reduced work hours and schedule flexibility).

Differences in cultural expectations of what it means to be a good mother versus a good father may partly explain these gender differences (Hays, 1996). In most families, mothers, not fathers, still assume the role of primary caretaker. Given that the ideology of intensive mothering is still dominant in the United States, it is not surprising that mothers' time in domestic labor is sensitive to their own availability and has very little to do with their husbands' policy use and availability. When a policy affords them more availability, mothers use it to increase housework time (reduced work hours) and child care time (work at home). Fathers do not use any additional flexibility or time that work policies afford them to perform additional care work. The finding that fathers' domestic labor time is more closely associated with their wives' policy use instead of their own is also consistent with previous research showing that fathers step in to assist with housework only when mothers are not available (Barnett \& Baruch, 1987; Brayfield, 1995; Deutsch, Lussier, \& Servis, 1993).

Some limitations of our study should be noted. The fact that we do not find stronger associations between workplace flexibility policies and domestic labor time could be due to a lack of statistical power, given our small sample size. Most nationally representative data sets with larger sample sizes, however, do not ask respondents detailed questions about their use of workplace flexibility and domestic work time for themselves or their partners. The unusually rich data used in this study allows examination of these issues but should be replicated with larger samples as such data become available.

One potential reason for the lack of statistical significance between policy use and care work responsibility in our longitudinal analysis may be due to the lack of within-person variance in the main measures of interest (Halaby, 2004). For instance, $92 \%$ of the sample of mothers had between a -1 and +1 unit change on the care work responsibility scale (ranging from 1 to 5), indicating that there was not much within-person change in care work responsibility during the study period. Also, the distribution of some of the policy months variables show little variation and are highly skewed: $79 \%$ of the mothers did not work reduced hours at all between survey waves, and $75 \%$ did not work at home. 
There are other potential explanations for the lack of effect of workplace policies on household labor. For example, employees may simply be using extra time that workplace flexibility policies afford them for leisure or volunteer activities, not housework or child care. Or perhaps considerable longterm changes in the workplace are necessary before workplace flexibility policies have a large impact on gendered family responsibilities. For instance, a worker may need to use multiple policies for many years before his or her housework and child care time are affected. In addition to cumulative effects, policy use by husband and wife may have interactive effects; for example, both members of a couple may need to use the same policy simultaneously to achieve a noticeable impact on total domestic labor time within the family. We encourage future researchers to consider these possibilities.

Overall, however, our results provide convincing evidence that workplace flexibility policies in the aggregate do not contribute to the gender gap in housework among dual-earner couples at present. Although women use workplace flexibility to directly alter their time in housework and child care, this does not necessarily translate into either increased time in housework or increased responsibility for domestic labor in the home. In contrast, men do not seem to use their own workplace flexibility to alter their time in housework or child care but do react to the changes in their wives' housework time produced by their wives' workplace flexibility.

\section{Appendix A}

\section{Regression Results Predicting Total Weekly Hours of Housework}

\begin{tabular}{|c|c|c|c|c|c|c|c|c|}
\hline \multirow[b]{2}{*}{ Variable } & \multicolumn{4}{|c|}{ Mothers } & \multicolumn{4}{|c|}{ Fathers } \\
\hline & Model 1 & $S E$ & Model 2 & $S E$ & Model 1 & $S E$ & Model 2 & $S E$ \\
\hline \multicolumn{9}{|l|}{ Respondent's policy use } \\
\hline Schedule flexibility & $-4.39 *$ & 1.84 & $-5.07 * *$ & 1.92 & -1.42 & 1.72 & -2.47 & 1.71 \\
\hline Work at home & 3.56 & 2.89 & 3.28 & 2.89 & -2.45 & 4.10 & -0.99 & 4.02 \\
\hline Reduced work hours & 2.49 & 2.23 & 3.01 & 2.24 & 2.02 & 6.69 & 6.69 & 6.64 \\
\hline \multicolumn{9}{|l|}{ Spouse's policy use } \\
\hline Schedule flexibility & & & 0.65 & 1.91 & & & $4.20 *$ & 1.74 \\
\hline Work at home & & & 1.15 & 4.26 & & & 0.18 & 2.44 \\
\hline Reduced work hours & & & -9.22 & 7.24 & & & $-3.31 \dagger$ & 2.01 \\
\hline$R$ squared & .12 & & .13 & & .12 & & .18 & \\
\hline$N$ & 110 & & 110 & & 110 & & 110 & \\
\hline
\end{tabular}

Note: All models include controls for working overtime, education, logged income, percentage of family income earned by respondent, attitudes, number of children, and spouse's housework hours. $\dagger p<.10 . * p<.05$. ** $p<.01$. 


\begin{tabular}{|c|c|c|c|c|c|c|c|c|}
\hline \multirow[b]{3}{*}{ Variable } & \multicolumn{4}{|c|}{ Appendix B } & \multicolumn{4}{|c|}{ kly Hours of Child Care } \\
\hline & \multicolumn{4}{|c|}{ Mothers } & \multicolumn{4}{|c|}{ Fathers } \\
\hline & Model 1 & $S E$ & Model 2 & $S E$ & Model 1 & $S E$ & Model 2 & $S E$ \\
\hline \multicolumn{9}{|l|}{ Respondent's policy use } \\
\hline Schedule flexibility & -1.07 & 2.31 & -1.90 & 2.45 & -0.82 & 2.07 & -1.57 & 2.11 \\
\hline Work at home & $10.13^{* *}$ & 3.71 & $9.94 * *$ & 3.77 & -3.24 & -2.66 & 4.98 & \\
\hline Reduced work hours & -1.02 & 2.83 & -1.00 & 2.88 & 8.59 & 8.06 & 11.43 & 8.21 \\
\hline \multicolumn{9}{|l|}{ Spouse's policy use } \\
\hline Schedule flexibility & & & 1.15 & 2.44 & & & 2.93 & 2.13 \\
\hline Work at home & & & 1.66 & 5.48 & & & 1.10 & 3.14 \\
\hline Reduced work hours & & & -5.26 & 9.37 & & & 0.99 & 2.50 \\
\hline$R$ squared & .14 & & .15 & & .10 & & .13 & \\
\hline$N$ & 110 & & 110 & & 110 & & 110 & \\
\hline
\end{tabular}

Note: All models include controls for working overtime, education, logged income, percentage of family income earned by respondent, attitudes, number of children, and spouse's child care hours. $* * p<.01$.

\section{Notes}

1. Whether the decline in parental availability has led to a decline in actual parental time with children, however, is a debated issue (Sayer, Bianchi, \& Robinson, 2004).

2. Detailed comparisons to the mothers and fathers in the National Longitudinal Sample of Youth from years 1991 to 1998 were used here and are available on request.

3 . The Hausman test tests the null hypothesis that the coefficients estimated by the efficient random-effects estimator are the same as the ones estimated by the consistent fixedeffects estimator (Halaby, 2004; Snijders \& Bosker, 1999). If the coefficients are similar, then it is preferable to use the random-effects model.

4. The original sample included 321 women; 196 of these women $(61 \%)$ were successfully interviewed at Time 4. Of the 196 women interviewed at this time, 163 (83\%) were employed. Of these employed women, 148 were married or living with a partner at Time 4 . Interviews of the women's husbands or cohabiting partners were successfully completed for 113 cases. Three of the husbands or partners were unemployed at Time 4, resulting in a final sample of 110 employed women with employed spouses. We compared the women in the smaller sample of 110 to the women in the larger sample of 163 to see if there were any substantive differences on the main variables used in the analysis. There was none.

5 . We checked to see that the policies were equally available to women and men in our sample. Work at home ( $28 \%$ women vs. $20 \%$ men) and schedule flexibility ( $87 \%$ women vs. $79 \%$ men) were approximately equally available to women and men. Part-time work was significantly more available to women than men in our sample ( $36 \%$ women vs. $2 \%$ men).

6. Various thresholds for the "work at home" policy variable were investigated, including 1 hour (17\% mothers and $12 \%$ fathers use policy) and 8 hours (9\% mothers and $4 \%$ fathers use policy) of work at home. Results using these alternative thresholds showed few differences and are available on request. 
7. We explored measuring each policy as a continuous variable: days per week of schedule flexibility, hours per week of work at home, and hours per week of part-time work. In the end, we decided to define policy use as a dummy variable for theoretical reasons. We expect there to be differences in domestic work time between those who use a policy beyond a given threshold and those who do not; we do not expect there to be small incremental effects of policy use (e.g., increasing flexible policy use from 1 day per week to 2 days per week).

8. Of the 110 women in dual-earner couples at Time 4, 90 were also in dual-earner couples at Time 1 . Four women with missing data on the care work responsibility measure were also excluded from the sample.

9. Data on education were not collected at the fourth wave of the survey, so we rely on education measured in the first wave for both analyses. This is unlikely to affect the results, because the majority of respondents' education would remain constant between waves, given the age of respondents at the initial survey: 20 and 41 years old.

\section{References}

Aryee, S., Luk, V., \& Stone, R. (1998). Family-responsive variables and retention-relevant outcomes among employed parents. Human Relations, 51(1), 73-87.

Barnett, R. C., \& Baruch, G. K. (1987). Determinants of fathers' participation in family work. Journal of Marriage and Family, 49, 29-40.

Becker, G. S. (1991). A treatise on the family. Cambridge, MA: Harvard University Press.

Beers, T. M. (2000). Flexible schedules and shift work: Replacing the 9-to-5 workday? Monthly Labor Review, 123(6), 33-40.

Bergmann, B. (1998). Watch out for "family friendly" policies. Dollars and Sense: The Magazine of Economic Justice, 215, 10-11.

Bianchi, S. M. (2000). Maternal employment and time with children: Dramatic change or surprising continuity? Demography, 37, 401-414.

Bianchi, S. M., Milkie, M. M., Sayer, L. C., \& Robinson, J. P. (2000). Is anyone doing the housework? Social Forces, 79, 191-228.

Blood, R. O., \& Wolfe, D. M. (1960). Husbands and wives: The dynamics of married living. New York: Free Press.

Bohen, H. H., \& Viveros-Long, A. (1981). Balancing jobs and family life: Do flexible work schedules help? Philadelphia: Temple University Press.

Bond, J., \& Galinsky, E. M. (2001). National study of the changing workforce, 1992 and 1997. New York: Families and Work Institute.

Brayfield, A. (1995). Juggling jobs and kids: The impact of employment schedules on fathers' caring for children. Journal of Marriage and Family, 57, 321-332.

Brines, J. (1994). Economic dependency, gender, and the division of labor at home. American Journal of Sociology, 100, 652-688.

Casper, L. M., \& Bianchi, S. (2002). Continuity and change in the American family. Thousand Oaks, CA: Sage.

Coverman, S. (1983). Gender, domestic labor time, and wage inequality. American Sociological Review, 48, 623-637.

Deutsch, F. M., Lussier, J. B., \& Servis, L. J. (1993). Husbands at home: Predictors of paternal participation in childcare and housework. Journal of Personality and Social Psychology, 65, 1154-1166. 
Gerson, J., \& Kraut, R. E. (1988). Clerical work at the home or in the office: The difference it makes. In K. E. Christensen (Ed.), The new era of home-based work (pp. 49-64). Boulder, CO: Westview.

Glass, J. (2004). Blessing or curse? Work-family policies and mother's wage growth over time. Work and Occupations, 31, 1-28.

Glass, J., \& Fujimoto, T. (1995). Employer characteristics and the provision of family responsive policies. Work and Occupations, 22, 380-411.

Golden, L. (2001). Flexible work time: Correlates and consequences of work scheduling. American Behavioral Scientist, 44, 1157-1178.

Goldscheider, F. K., \& Waite, L. J. (1991). New families, no families? The transformation of the American home. Berkeley: University of California Press.

Grover, S. L., \& Crooker, K. J. (1995). Who appreciates family-responsive human resource policies: The impact of family-friendly policies on the organizational attachment of parents and non-parents? Personnel Psychology, 48, 271-288.

Gurstein, P. (1991). Working at home and living at home: Emerging scenarios. Journal of Architectural and Planning Research, 8, 164-180.

Halaby, C. N. (2004). Panel models in sociological research: Theory into practice. Annual Review of Sociology, 30, 507-544.

Hays, S. (1996). The cultural contradictions of motherhood. New Haven, CT: Yale University Press.

Hewlett, S. A. (1991). When the bough breaks: The cost of neglecting our children. New York: Basic Books.

Hochschild, A. (1989). The second shift: Working parents and the revolution at home. New York: Viking.

Ishii-Kuntz, M., \& Coltrane, S. (1992). Predicting the share of household labor: Are parenting and housework distinct. Sociological Perspectives, 35, 629-647.

Jacobs, J. A., \& Gerson, K. (2004). The time divide: Work, family, and gender inequality. Cambridge, MA: Harvard University Press.

Kelly, E. (1999). Theorizing corporate family policies: How advocates built the "business case" for "family-friendly" policies. In Toby Parcel (Ed.), Research in the sociology of work (pp. 169-202). Greenwich, CT: JAI.

Kennedy, P. (2003). A guide to econometrics. Cambridge, MA: MIT Press.

Kraut, R. E. (1989). Telecommuting: The trade-offs of homework. Journal of Communications, 39, 19-47.

Kraut, R. E., \& Grambsch, P. (1987). Home-based, white-collar work: Lessons from the 1980 census. Social Forces, 66, 410-426.

Meyer, C. S., Mukerjee, S., \& Sestero, A. (2001). Work-family benefits: Which ones maximize profits? Journal of Managerial Issues, 13(1), 28-44.

Moen, P., \& Yu, Y. (2000). Effective work/life strategies: Working couples, work conditions, gender, and life quality. Social Problems, 47, 291-326.

Nock, S. L., \& Kingston, P. W. (1988). Time with children: The impact of couples' work-time commitments. Social Forces, 67, 59-85.

Osnowitz, D. (2005). Managing time in domestic space: Home-based contractors and household work. Gender and Society, 19(1), 83-103.

Presser, H. B. (1994). Employment schedules among dual-earner spouses and the division of household labor by gender. American Sociological Review, 59, 348-364.

Sayer, L., Bianchi, S., \& Robinson, J. P. (2004). Are parents investing less in children? Trends in mothers' and fathers' time with children. American Journal of Sociology, 110(1), 1-43. 
Scandura, T. A., \& Lankau, M. J. (1997). Relationships of gender, family responsibility and flexible work hours to organizational commitment and job satisfaction. Journal of Organizational Behavior, 18(4), 377-391.

Silver, H. (1993). Homework and domestic work. Sociological Forum, 18, 181-204.

Silver, H., \& Goldscheider, F. (1994). Flexible work and housework: Work and family constraints on women's domestic labor. Social Forces, 72, 1103-1119.

Snijders, T., \& Bosker, R. (1999). Multilevel analysis. London: Sage.

Stratton, L. S. (2001). Why does housework lower women's wages? Testing hypotheses involving job effort and hours flexibility. Social Science Quarterly, 82, 67-76.

West, C., \& Zimmerman, D. H. (1987). Doing gender. Gender and Society, 1, 125-151.

Wharton, C. S. (1994). Finding time for the "second shift": The impact of flexible work schedules on women's double days. Gender and Society, 8, 189-205.

Zellner, A. (1962). An efficient method of estimating seemingly unrelated regressions and tests for aggregation bias. Journal of the American Statistical Association, 57, 348-368.

Zick, C. D., Bryant, W. K., \& Osterbacka, E. (2001). Mothers' employment, parental involvement, and the implications for intermediate child outcomes. Social Science Research, 30, 25-49. 